\title{
Multiple Electrosensory Maps in the Medulla of Weakly Electric Gymnotiform Fish. I. Physiological Differences
}

\author{
Caroly A. Shumway \\ Neurobiology Unit, Scripps Institution of Oceanography, UCSD, La Jolla, California 92093
}

\begin{abstract}
The electrosensory lateral line lobe in the weakly electric gymnotiform fish Eigenmannia contains 3 topographic maps of high-frequency (tuberous) electroreceptive information from the body surface. The maps receive identical primary afferent input since axonal collaterals of both amplitude- and phase-coding afferents project to all 3 maps (Heiligenberg and Dye, 1982). Response properties of the amplitude-coding pyramidal neurons in the multiple maps were investigated in order to determine whether the maps differ physiologically. Units in the lateral map have larger receptive fields and are more sensitive than units in the centromedlal map. The former units respond more phasically and with shorter latencies to step changes in stimulus amplitude (measured from the stimulus onset to the maximum response). Although $75 \%$ of pyramidal cells in all maps show a center-surround receptive-field organization, the strength of the inhibitory surround varies among maps, tending to be weakest for units in the lateral map and strongest for units in the centromedial map. Pyramidal neurons also differ in their responses with respect to the temporal frequency of amplitude modulations; the majority of units in the lateral map prefer high temporal frequencies, while those in the centromedial map prefer low frequencies. These results suggest that the multiple electrosensory maps could provide the initial separation of spatial and temporal processing of sensory information, much as has been suggested for $X$ and $Y$ ganglion cells in the cat retina (Shapley and Perry, 1986). The centromedial map could provide high spatial contrast with correspondingly poor temporal resolution, while the more sensitive units in the lateral map could best provide information about temporal changes in stimulus amplitude.
\end{abstract}

Multiple sensory representations of the environment are a common component of mammalian sensory systems (for reviews, see Woolsey, 1981a, b, 1982; Kaas, 1982, 1983; Peters and Jones, 1985a, b, 1986). Multiple maps are found in the neocortex and thalamic areas of the somatosensory, visual, and auditory systems and are also present in the brain-stem areas of the auditory system, such as the cochlear nuclei and olivary complex. Although multiple sensory maps are most highly evolved

\footnotetext{
Received Oct. 31, 1988; revised May 31, 1989; accepted June 5, 1989.

This work was supported by National Institutes of Mental Health grant 2-RO1MH-26149 to Walter Heiligenberg. I thank Ted Bullock, Walter Heiligenberg, Kip Keller, Jim Enright, and the anonymous reviewers for helpful criticism of the manuscript.

Correspondence should be addressed to Caroly $\mathrm{A}$. Shumway, Division of Biology 216-76, California Institute of Technology, 1201 E. California Boulevard, Pasadena, CA 91125.

Copyright (C) 1989 Society for Neuroscience $0270-6474 / 89 / 124388-12 \$ 02.00 / 0$
}

in mammals, they are also found in other vertebrates: two wellknown examples are the cochlear nuclei of birds and the electrosensory maps in the medulla of weakly electric teleosts. The nucleus magnocellularis and nucleus angularis of birds receive identical auditory afferent input, but different synaptic interactions within these nuclei result in the separate processing of stimulus phase in the nucleus magnocellularis and stimulus intensity in the nucleus angularis (Boord and Rasmussen, 1963; Sullivan and Konishi, 1984; Takahashi et al., 1984). Both orders of weakly electric teleosts, the Gymnotiformes and Mormyriformes, have multiple sensory maps in the first-order electrosensory nucleus, the electrosensory lateral line lobe (ELL). These fish apparently evolved the electric sense independently and have highly specialized brains for processing of electrosensory information (see Bell and Szabo, 1986; Carr and Maler, 1986).

This study examines the physiological properties of multiple maps in weakly electric fish. Weakly electric fish generate an electric field for object localization and social communication. The electric field is modulated in phase and amplitude by objects, as well as by the electric fields of conspecifics; the modulatory effects on the fish's field and the subsequent neural coding of phase and amplitude information have been studied extensively (see Bastian, 1986c; Heiligenberg, 1986, for reviews). The ELL of gymnotiform fish contains 4 maps of electrosensory information from the body surface; 3 of these receive high-frequency (tuberous) electroreceptive input, and 1 receives low-frequency (ampullary) input. The 3 tuberous maps (centromedial, centrolateral, and lateral) provide an attractive, simple system to address the functional significance of multiple maps. The maps receive identical afferent information from axonal collaterals of the amplitude- and phase-coding primary afferents (P-and T-type, respectively) (Heiligenberg and Dye, 1982). There are fewer than 1500 amplitude-coding pyramidal cells and 500 phase-coding spherical cells in each map (Maler, 1979; Carr et al., 1986; Shumway, 1989). No intermap connections have been found. The present study characterizes the physiological properties of pyramidal cells in the 3 electrosensory tuberous maps of Eigenmannia in an attempt to identify the functional significance of the multiple maps. The anatomical bases for the physiological differences reported in this study are described in the accompanying paper (Shumway, 1989). Preliminary results of this work have been reported in abstract form (Shumway, 1985, 1986).

\section{Materials and Methods}

All experiments were performed on 10- to 15-cm-long Eigenmannia sp. A fish was immobilized and the myogenic electric organ discharge (EOD) greatly attenuated with an intramuscular injection of $10 \mu \mathrm{l}$ of 1$2 \%$ Flaxedil. The fish was suspended in the water of the experimental 
tank with a foam-lined clamp and respirated with a steady flow of aerated water $\left(26-27^{\circ} \mathrm{C}, 3-5 \mathrm{~K} \Omega \cdot \mathrm{cm}\right)$. The body was entirely submerged except for the dorsal portion of the head. A suction electrode on the tip of the tail monitored the spinal volley associated with the remnant EOD. All surgical techniques were preceded by topical application of $2 \% \mathrm{li}-$ docaine. After removing the skin overlying the parietal bone, a Plexiglas holder was glued to the bone in order to stabilize the preparation (Vetbond tissue adhesive). A small hole above the right ELL was drilled through the skull, and the meninges were carefully removed with fine forceps. A fish Ringer's solution was regularly applied to keep the brain moist. A silver-wire ground electrode was placed on the bone next to the hole. For recordings from primary afferents, the posterior branch of the lateral line nerve, which innervates trunk electroreceptors, was exposed. After surgery, the clamp holding the fish was removed such that the fish was held in place only by the Plexiglas holder and the respirator. This enabled the recording of units with receptive fields ranging over most of the body surface, rostrally to the operculum and caudally to the suction electrode on the tail. Mechanical lateral stabilization of the fish was enhanced by placing a Plexiglas support constructed of six $3 \times 60 \mathrm{~mm}$ vertically oriented rods on the opposite side of the fish.

The electrical stimulus used was a continuous sinusoidal signal adjusted to the frequency of the animal's EOD prior to curarization. The stimulus was isolated from ground with a constant-voltage stimulus isolation unit and was applied via silver-wire electrodes in the mouth and near the tail to generate a geometry similar to that of the animal's own EOD. The stimulus was monitored in the water with a pair of electrodes positioned laterally $1 \mathrm{~cm}$ from the head and perpendicularly to the body surface, directly behind the gills. The amplitude of the stimulus at this location was $1 \mathrm{mV} / \mathrm{cm}$.

Pyramidal cells were recorded extracellularly with indium-plated glass micropipettes (Frank and Becker, 1964), with tip diameters of $5 \mu \mathrm{m}$ and impedances of $0.5-2 \mathrm{M} \Omega$. These electrodes provided stable recordings up to $1 \mathrm{hr}$. In order to reduce the stimulus artifact in the recording signal, a similar electrode was placed on the brain to serve as a reference. The reference signal and the signal from the recording electrode were fed into a differential AC preamplifier (Grass P-15) for common-mode rejection and amplification. A copy of this amplified signal, delayed by 1 stimulus cycle and inverted, was then added to the undelayed signal to attenuate the residual periodic artifact. This process, however, could not eliminate transients caused by step changes in amplitude.

Pyramidal cells were characterized as E or I units with whole-body stimulation (i.e., electrodes in mouth/tail orientation). This stimulus arrangement was used to ensure that all electroreceptors were optimally stimulated (Partridge et al., 1981). Threshold sensitivities to amplitude modulation, time constants of adaptation, and latencies were also measured with whole-body stimulation. Tests of amplitude-modulation sensitivity were performed with the stimulus being amplitude-modulated by a $4 \mathrm{~Hz}$ sinusoid to depths ranging from -6 to $-60 \mathrm{~dB}$, with $0 \mathrm{~dB}$ being $100 \%$ modulation of the $1 \mathrm{mV} / \mathrm{cm}$ stimulus. Threshold sensitivity to amplitude modulations was measured by correlating the period histogram obtained from 64 modulation cycles at a suprathreshold magnitude of modulation with period histograms constructed from single modulation cycles at each depth of modulation tested. The suprathreshold stimulus was $-10 \mathrm{~dB}$ for most units and $-6 \mathrm{~dB}$ for those units which did not respond well to $-10 \mathrm{~dB}$. Threshold was defined as that depth of amplitude modulation at which $68 \%$ of the correlation coefficients computed from single modulation cycles were greater than 0 . (See Rose and Heiligenberg, 1986, for justification of this method.)

Receptive-field sizes were measured with a moveable electrode positioned directly on the skin. This electrode was part of a longitudinal array of 7 electrodes attached to a micromanipulator. Each electrode was constructed of a silver wire within a fire-polishcd glass pipette of $1 \mathrm{~mm}$ diameter. The electrodes were $4 \mathrm{~mm}$ apart, and the entire array spanned a distance of $24 \mathrm{~mm}$. After the whole-body stimulation had been turned off, a local stimulus, modulated sinusoidally at $2-4 \mathrm{~Hz}$ and at $-10 \mathrm{~dB}$, was applied through 1 electrode on the skin and the reference electrode in the mouth. As this stimulus results in a higher local current density than that of the whole-body stimulus, the mean amplitude of the signal from the function generator was reduced to $1 / 10$ the amplitude of the whole-body stimulus. The cell's response to the amplitude-modulated (AM) stimulus was recorded at a particular dorsoventral level, and the electrode was then displaced longitudinally in steps of $2 \mathrm{~mm}$. At each point, the cell's response to the AM stimulus was recorded. The electrode was then moved by $1 \mathrm{~mm}$ to a new dorsoventral level, and the longitudinal scan repeated. Average response histograms were constructed for each test site. Testing was continued slightly beyond the point of no audible modulation-related change in activity of the unit. The receptive-field size was determined as that region encompassing neuronal responses which were at least $60 \%$ of the peak response obtained at the optimal electrode position. Receptive-field area was calculated as an ellipse by using the dorsoventral and rostrocaudal dimensions of the $60 \%$ region.

For tests of direction selectivity, an analog plotter moved a $1.5 \mathrm{~cm}$ wide metal or plastic plate parallel to the fish over a path of $10 \mathrm{~cm}$, at a lateral distance of $1 \mathrm{~cm}$, and with a linear velocity of $6 \mathrm{~cm} / \mathrm{sec}$.

Extracellular potentials, along with stimulus synchronization pulses, were tape-recorded (TEAC 22-4) at 71/2 inches/sec and were subsequently analyzed on a DEC PDP $11-40$ computer. Neuronal responses compiled in spike-rate histograms were usually averaged for 40-50 AM cycles. For all measurements except those of time constant of adaptation and latency, bin width was an integer multiple of the period of the stimulus cycle. Time constants of adaptation, defined as the time required for the neuron's response to decay to $37 \%$ of its maximum value, and latency of the maximum response with respect to a step change in amplitude were measured from spike-rate histograms with the interactive program SPARTA; the bin width for these measurements was the period of one stimulus cycle (between $2-5 \mathrm{msec}$ ). Statistical procedures used to compare the samples from the 3 maps were a parametric analysis of variance followed by a Tukey test for unequal sample sizes. Comparisons of $E$ and I units within each map were performed with a Student's $t$-test. In both cases, the alpha level was set at 0.05 . All measures of variability here are SEs.

Since it was essential to know in which particular map each unit was located, recordings from a single electrode track were marked by small electrolytic lesions. To reduce the possibility of including data from primary afferents, a unit was not included in the analysis if the lesion site was not in the pyramidal cell layer. Three lesion sites were generally marked per fish, and a total of 43 fish were used. Not all recordings, however, were sufficiently stable to test all parameters.

\section{Results}

\section{Background}

There are 2 physiologically distinct classes of pyramidal cells: E cells, which are excited by a rise in EOD amplitude, and I cells which are inhibited by a rise in EOD amplitude and are excited by a fall in amplitude (Scheich, 1977; Bastian, 1981b; Matsubara, 1982; Saunders and Bastian, 1984; see Bastian, 1986c, for review). E cells, or basilar pyramidal cells, receive monosynaptic input from P-type primary afferents, while I cells, or nonbasilar cells, receive disynaptic input via an inhibitory granule cell (Maler et al., 1981).

\section{Spatial response properties}

Receptive-field properties of pyramidal cells in Apteronotus were extensively investigated by Bastian (1981b) before the existence of multiple maps was known. The present study repeated such measurements on Eigenmannia in search of possible map-specific differences. Receptive-field sizes of pyramidal cells were assessed quantitatively by determining the response of a unit to a local, sinusoidally AM electrical stimulus applied locally (see Materials and Methods for further details). As shown in Figure $1 A$, units in the centromedial map had the smallest receptive fields [ $24 \pm 3.4 \mathrm{~mm}^{2}$ (SE), $n=18$ ]; those in the centrolateral map had larger receptive fields $\left(44.5 \pm 7.9 \mathrm{~mm}^{2}, n=15\right)$; and those in the lateral map had the largest receptive fields $(55.1 \pm$ $6.0, n=21$ ). The mean receptive-field size of units in the lateral map was therefore more than twice as large as the mean receptive-field size of units in the centromedial map (significant, Tukey test, $p<0.05$ ). The receptive-field size of 9 P-type primary afferents was measured in a similar fashion. The mean receptivefield area of these units, all with receptive fields on the trunk, 
A

RECEPTIVE FIELD SIZE

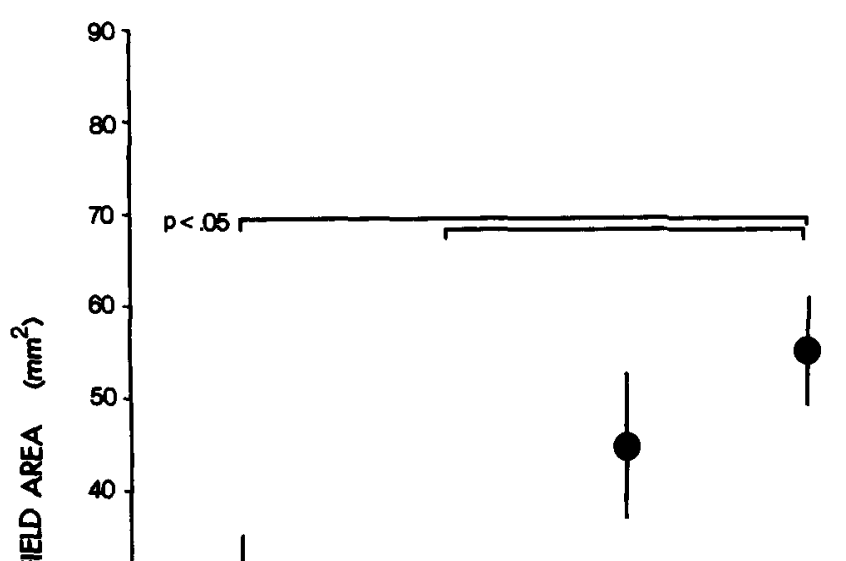

C

$C M$

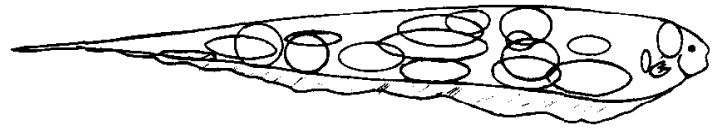

$\mathrm{Cl}$

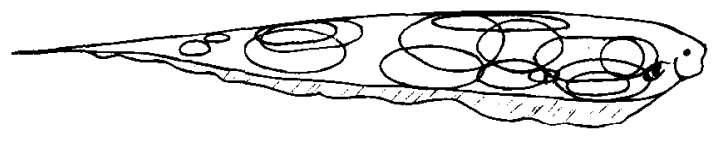

L
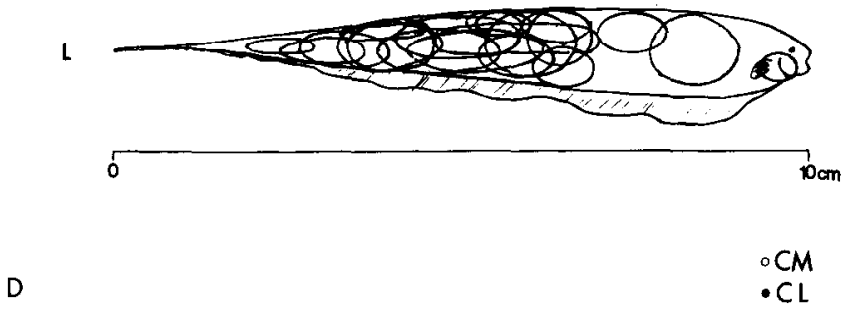

D

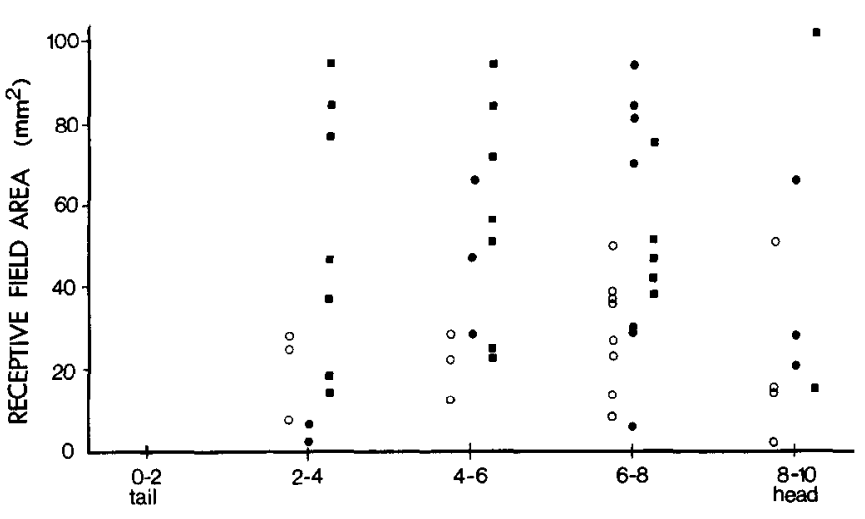

RECEPTIVE FIELD ROSTRO-CAUDAL POSITION (cm)

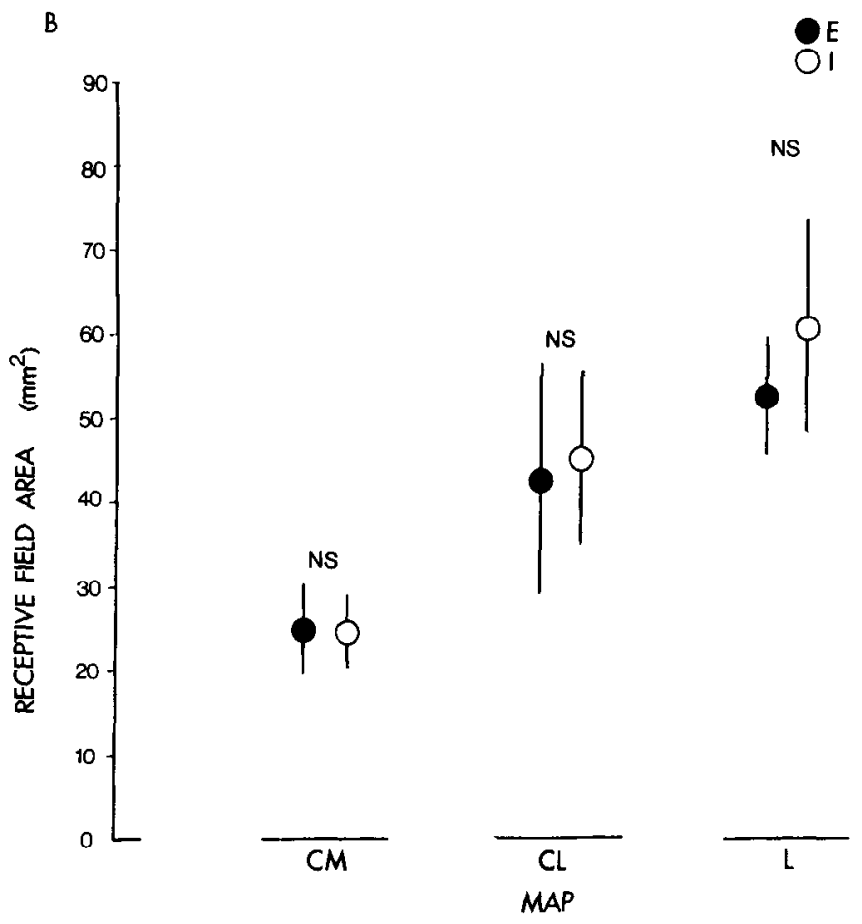

was $27.1 \pm 8.0 \mathrm{~mm}^{2}$. The mean receptive-field area of units in the centromedial map was thus nearly of the same size as the mean area of the primary afferents, while the mean receptivefield size of units in the lateral map was more than twice as large as the mean value for the afferents $(p<0.05)$.

The number of $E$ and I units varied in the samples from each map. To ensure that the receptive-field differences among maps were not artifacts of the different numbers of $E$ and $I$ units sampled, the mean receptive-field sizes of $E$ and $I$ units within each map were compared (Fig. $1 B$ ). E and I receptive-field sizes within each map were not significantly different, as judged by a Student's $t$-test $[n=5 \mathrm{E}, 13$ I (CM map); 5E, 10I (CL map); and $15 \mathrm{E}, 6 \mathrm{I}$ (L map)].

The rostrocaudal location of the receptive fields in each map was plotted in order to determine whether the differences in receptive-field size could potentially be due to a sampling bias in recording from different rostrocaudal locations among the maps. Figure $1 C$ shows that the receptive fields of units in each 
A

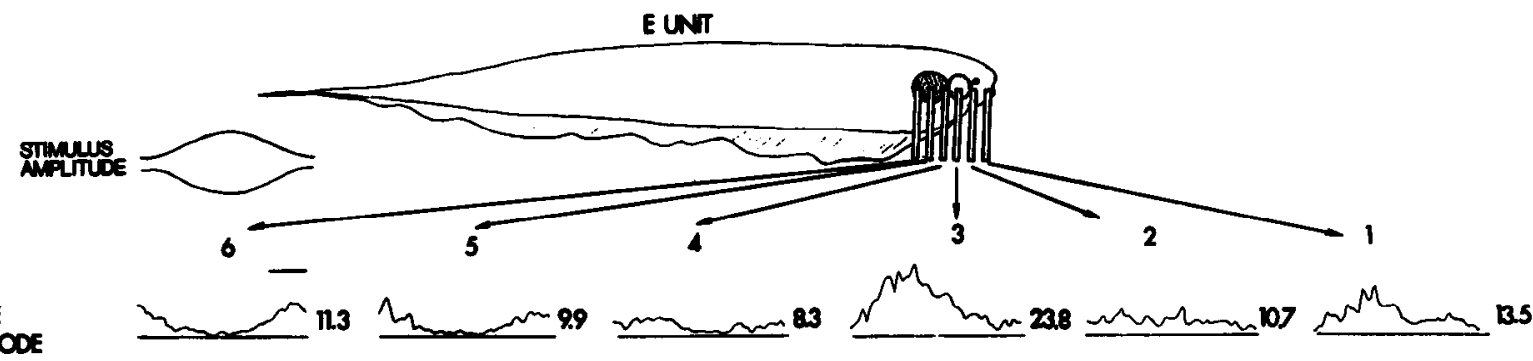

ELECTROOE
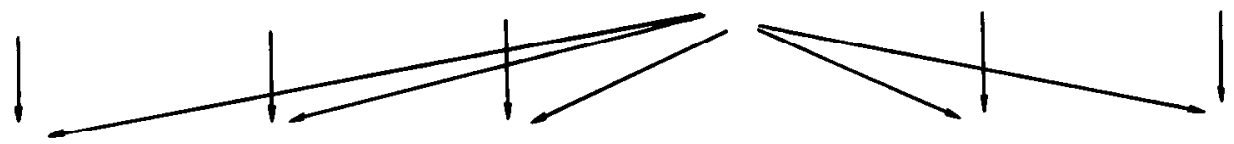

PAR of EECTRODES
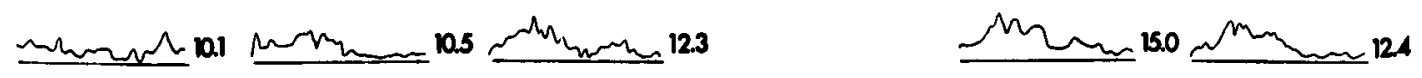

B

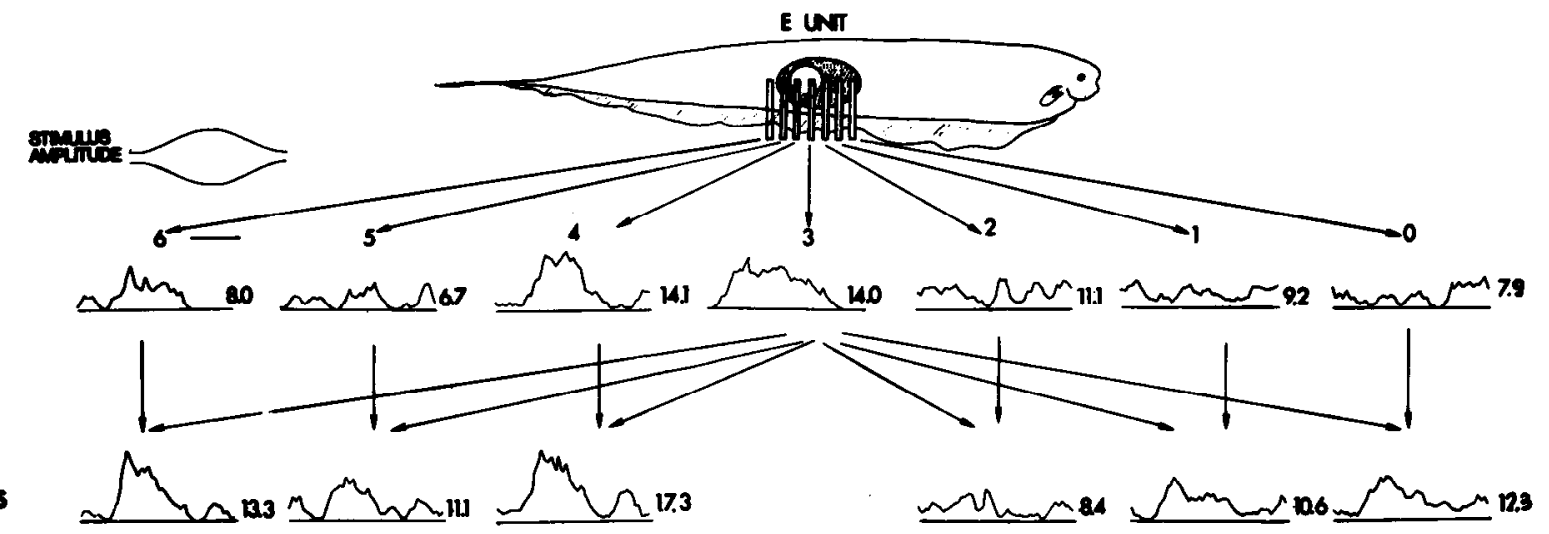

Figure 2. $A$ and $B$, Examples of center-surround receptive-field organization in $2 \mathrm{E}$ units from the centromedial and lateral maps, respectively. The open circle on the fish's body schematically represents the receptive-field center, and the dotted ellipse schematically represents the surround (not to scale). The histograms show the average response during the AM cycle. The spike rate (spikes/sec) is indicated to the right of each histogram. The top traces in $A$ and $B$ show the histograms of responses to a local sinusoidal AM stimulus presented through a single electrode at various electrode positions, ranging from 0 to 6 . (In $A$, position 0 is not represented as its position was rostral to that of the fish.) $\mathrm{E}$ units are excited by a rise in stimulus amplitude in the center of their receptive field (electrode positions 3 in $A ; 3$ and 4 in $B$ ). The lower traces for each unit show the response to presentation of the same stimulus through a pair of electrodes, with the first electrode in the center of the receptive field, and the second electrode being varied from position 0 to 6 . $A$, This unit from the centromedial map had an inhibitory surround on the caudal side of the excitatory center (top trace, positions 4-6). Simultaneous stimulation in the center and surround reduced the firing rate by $58 \%$, measured over 57 modulation cycles (bottom trace, electrode position 6). $B$, This unit from the lateral map had an inhibitory surround on both sides of the excitatory center, but the area of inhibition was much larger on the rostral side. Simultaneous stimulation of the center and surround (electrode position 2 ) reduced the firing rate by $40 \%$, measured over 14 modulation cycles. Bin width is 3 stimulus cycles. Horizontal calibration bar, 100 msec.

map covered the same range of positions on the body surface, although a larger fraction of the lateral units had receptive fields in the caudal portions of the trunk. A comparison of the receptive-field sizes of units in the 3 maps at each rostrocaudal location is shown in Figure $1 D$; it is obvious that the receptivefield size of lateral units tended to be greater and the receptivefield size of centromedial units tended to be smaller, although there is some overlap in the range. It should be noted that these 54 units are from 32 different fish ranging in size from 10 to 15 $\mathrm{cm}$ and that there would likely be an even greater separation in receptive-field size between the lateral and centromedial maps if units from a single fish could be compared.

\section{Center-surround receptive-field organization}

A center-surround receptive-field organization of pyramidal cells in the ELL of weakly electric fish has been suggested by anatomical studies of Maler and colleagues (1981) and was indirectly demonstrated by Bastian (1986a) and Shumway and Maler (1989) by manipulations which increased the size of the inhibitory responses caused by moving objects. Direct dem- onstration of center-surround antagonism requires the use of stationary stimuli because moving objects are known to cause both local increases and decreases in stimulus amplitude level (Heiligenberg, 1975; Hoshimiya et al., 1980; Bastian, 1981a) and because pyramidal cells are known to exhibit postexcitatory suppression (Bastian, 1981b; Saunders and Bastian, 1984; Shumway and Maler, 1989). A center-surround organization was demonstrated with the use of a stationary array of 7 electrodes. The array was positioned over the receptive field of a pyramidal cell such that the electrode in position 3 ( 0 being most rostral) was in the receptive-field center. The response of the unit was first tested with a local sinusoidal AM presented singly through each electrode in the array (Figs. 2 and 3, top traces). The stimulus was then again presented through electrode 3 , and the unit tested before and after the addition of a second identical stimulus in the periphery (Figs. 2 and 3, bottom traces). Both signals originated from the same constant-voltage stimulus isolation unit. These experiments could detect surround inhibition located rostrally or caudally of the center, but could not detect inhibition located dorsoventrally. 

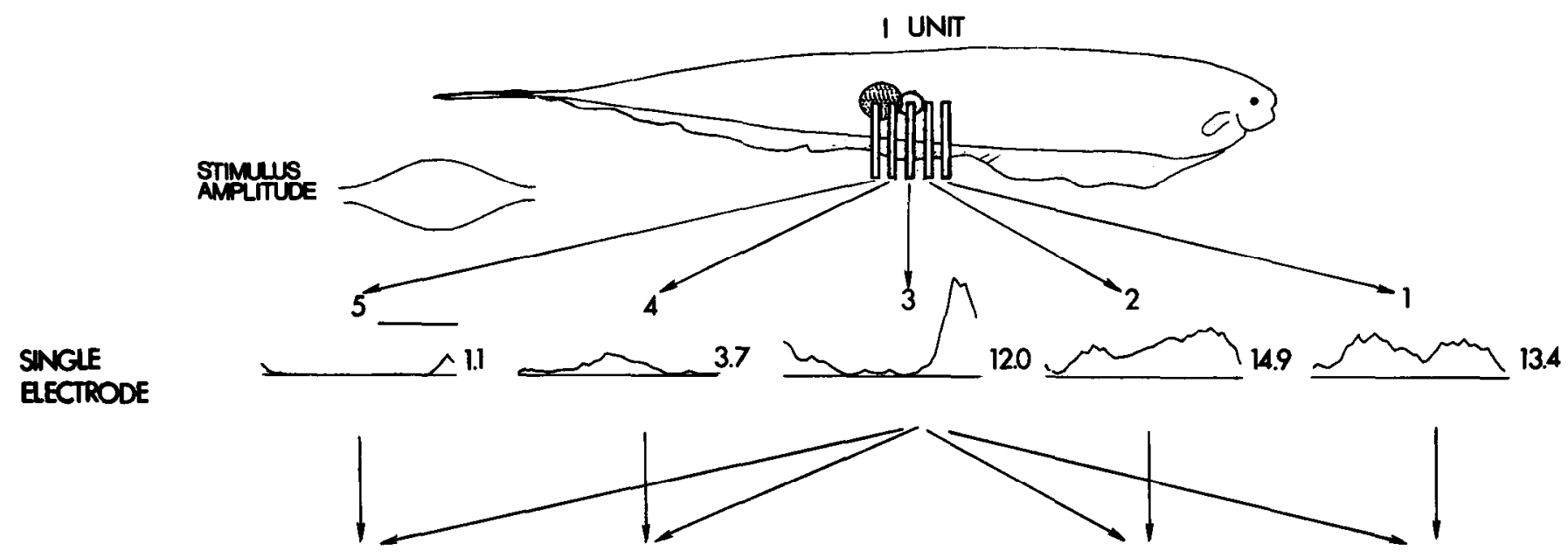

PAIR OF ELECTRODES

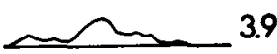

3.9
5.9

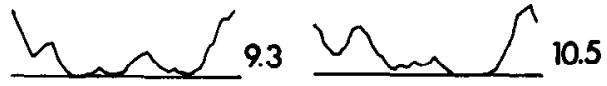

Figure 3. Example of center-surround receptive-field organization in an I unit from the centromedial map, presented as described in Figure 2. The open circle on the fish's body represents the center of the receptive field, and the dotted ellipse represents the surround. The surround of this unit was located on the caudal side of the receptive field only (electrodes in positions 4 and 5 ). In the center of the receptive field, the unit was excited by a decrease in stimulus amplitude, and in the surround of the receptive field the unit was excited, although not as vigorously, by an increase in stimulus amplitude. Simultaneous stimulation in the center (electrode position 3) and surround (electrode position 5) reduced the firing frequency of the cell by $68 \%$, measured over 26 modulation cycles. Bin width is 3 stimulus cycles. Horizontal calibration bar, 100 msec.

Figure 2, $A$ and $B$, shows the receptive-field organization of $2 \mathrm{E}$ units from the centromedial and lateral map, respectively. The receptive field of the centromedial map unit was $9.4 \mathrm{~mm}^{2}$ and was located on the head (Fig. 2A). In the center of the receptive field (top traces, electrode position 3 ), the unit was maximally excited by a rise in stimulus amplitude. In the surround, located primarily on the caudal side of the excitatory center, the unit was inhibited by an amplitude increase and was excited, although not as vigorously, by a decrease in stimulus amplitude. When a stimulus was applied to the center and a second stimulus applied to the surround in electrode position 6 (bottom trace), the firing rate (measured over the entire modulation cycle) dropped $58 \%$ from the initial value of 23.8 spikes/ sec obtained by stimulation of the center alone. On the rostral side of the excitatory center, "silent," shunting inhibition appears to be present: inhibition was not obvious with stimulation via electrode 2 alone, but the excitatory response due to stimulation in the center was reduced by the application of a second stimulus in position 2. The receptive field of the unit from the lateral map was situated on the trunk and was $47 \mathrm{~mm}^{2}$ (Fig. $2 B)$. In this case, the surround was located on both sides of the excitatory center but was largest on the rostral side. The maximum reduction in firing rate upon presentation of a second stimulus in the surround (electrode position 2) was $40 \%$.

Figure 3 shows the center-surround organization of an I unit from the centromedial map whose receptive field was on the trunk. The receptive-field area was $23.6 \mathrm{~mm}^{2}$. In the receptivefield center, the I unit was maximally excited by a decline in stimulus amplitude (top trace, electrode position 3). In the surround of the receptive field, located caudal to the receptive-field center, the unit responded weakly to an amplitude increase (electrode positions 4 and 5). Simultaneous stimulation in the center and surround (electrode position 5) reduced the number of spikes/ sec by $68 \%$.

A center-surround receptive-field organization was found in approximately $70 \%$ of the units in each map ( $n=11$ out of 15 , CM map; 6 out of 9, CL map; and 11 out of 15, L map). Since it was not possible to measure surround inhibition in the dorsoventral axis, the percentage of units with inhibitory surrounds is likely to be larger. Several units were found which responded preferentially to movement of a stimulus in a dorsal direction and were strongly inhibited by the opposite direction of movement, suggesting the presence of dorsoventral surrounds (also noted by Enger and Szabo, 1965). The possibility of dorsoventral surrounds was also suggested by the receptive-field measurements. Center-surround antagonism occurred slightly more often in I units $(85 \%, n=17 / 20)$ than $E$ units $(63 \%, n=12$ / 19).

The surround was typically not concentric. Only $18 \%$ of all units in the ELL with a center-surround receptive-field organization showed clear inhibitory responses on both sides of the excitatory center, with the strength of inhibition often unequal between sides. The remaining units were found to have a surround slightly more often rostral to the center than caudal (46 vs. $36 \%$ ). An asymmetric surround could potentially confer directional selectivity to a unit. Although some units did show directional preferences in response to a moving object, as previously reported by Enger and Szabo (1965) and Bastian (1981b), they were relatively rare. This suggests that center-surround organization in the ELL mainly serves to enhance spatial contrast.

The strength of surround inhibition was found to vary among maps, tending to be strongest for units in the centromedial map and weakest for units in the lateral map. The average decrease in peak firing rate upon simultaneous stimulation of the center and surround was $73 \%$ for $E$ and $I$ units in the centromedial map, compared with $58 \%$ for units in the centrolateral map and $41 \%$ for the lateral map. These values were determined with electrodes placed in optimal locations within the excitatory center and the inhibitory surround of the receptive field. 


\section{Temporal response properties}

Since the neurons in the maps differed in the size of their receptive fields, it seemed likely that they might show corresponding differences in the degree of receptor convergence, and, therefore, differences in their threshold sensitivity to amplitude modulations (Fig. 4; E units, filled circles; I units, open circles). Units were tested with a $4 \mathrm{~Hz}$, sinusoidally modulated stimulus at different depths of $\mathrm{AM}$, with $0 \mathrm{~dB}$ being $100 \%$ modulation of a $1 \mathrm{mV} / \mathrm{cm}$ stimulus. The mean threshold in the centromedial map was $-16.2 \pm 1.4(\mathrm{SE}) \mathrm{dB}$, or $15.5 \%$ modulation $(n=24)$; in the centrolateral map $-22.7 \pm 1.8 \mathrm{~dB}$, or $7.3 \%$ modulation $(n=22)$; and in the lateral map - $26.6 \pm 2.7 \mathrm{~dB}$, or $4.7 \%$ modulation $(n=16)$. Units in the lateral map were, therefore, more than 3 times as sensitive as units in the centromedial map $(p<0.05)$ while units in the centrolateral map were 2.1 times more sensitive $(p<0.05)$. Differences between $\mathrm{E}$ and I unit thresholds within each map were not significant $[n=10 \mathrm{E}, 14$ I (CM map); $8 \mathrm{E}$ and $14 \mathrm{I}(\mathrm{CL})$; and $10 \mathrm{E}, 6 \mathrm{I}(\mathrm{L})$ ]. Figure $4 B$ shows the AM threshold sensitivity of the units in the 3 maps as a function of the rostrocaudal location of their receptive field [n $n 21(\mathrm{CM}), 21(\mathrm{CL})$, and $13(\mathrm{~L})]$. Units represented in this figure are a subset of those in $4 A$, as receptive-field locations were not determined for all units. Lateral map units tended to be more sensitive than centromedial map units at every rostrocaudal location.

The rate of adaptation of pyramidal cells was examined by testing their response to step changes in stimulus amplitude (Fig. 5A). The time constant of adaptation, defined as the time required for a unit's response to decay to $37 \%$ of its peak value, was $30.1 \pm 4.1$ (SE) msec for units in the lateral map $(n=31)$, $57.9 \pm 8.8 \mathrm{msec}$ for units in the centrolateral map $(n=30)$, and $74.2 \pm 11.1 \mathrm{msec}$ for units in the centromedial map $(n=$ 32). The time constant of adaptation can serve as an inverse index of how phasic a unit is. By this criterion, units in the lateral map were, on average, 2.5 times as phasic as those in the centromedial map $(p<0.05)$ and 1.3 times as phasic as those in the centrolateral map (not significant, $0.10<p<0.05$ ). Figure $5 \mathrm{~A}$ also shows that there was much greater variability in the time constants of adaptation for units in the centromedial and centrolateral maps than for units in the lateral map.

These differences in the rate of adaptation were not due to a difference in numbers of $E$ and $I$ units sampled among maps; the time constants of $E$ and $I$ units within each map were not significantly different $[\mathrm{L}$ map: mean for $\mathrm{E}$ units $=33.3 \pm 5.4$ msec $(n=22)$, mean for I units $=22.2 \pm 4.0 \mathrm{msec}(n=9)$; CL map: $x(\mathrm{E})=56.2 \pm 15.7(n=12) ;(x) \mathrm{I}=59.1 \pm 10.6(n=$ 18); and CM map: $\bar{x}(\mathrm{E})=98.1 \pm 19.1(n=11), \bar{x}(\mathrm{I})=61.7$ $\pm 13.1(n=21)]$.

Examples of the response of $\mathrm{E}$ and $\mathrm{I}$ units in the different maps to step changes in stimulus amplitude are shown in Figure $5 B$. These units are shown as representatives because their time constants approximated the mean value of the units in each map. This figure also illustrates the latency of the responses to a step change in stimulus amplitude. Units from the centromedial map showed a considerable lag in their peak response onset. The latency of the peak response was measured with respect to the step increase or decrease of the stimulus amplitude, respectively, for $\mathrm{E}$ and I units (Fig. 6). The mean latency of units was $22 \pm 3.2$ (SE) msec in the lateral map $(n=24)$; $33.3 \pm 5.9 \mathrm{msec}$ in the centrolateral map $(n=15)$; and $49.8 \pm$ $5.5 \mathrm{msec}$ in the centromedial map $(n=24)$. Units of the lateral map, therefore, reached a peak firing rate more than twice as
A
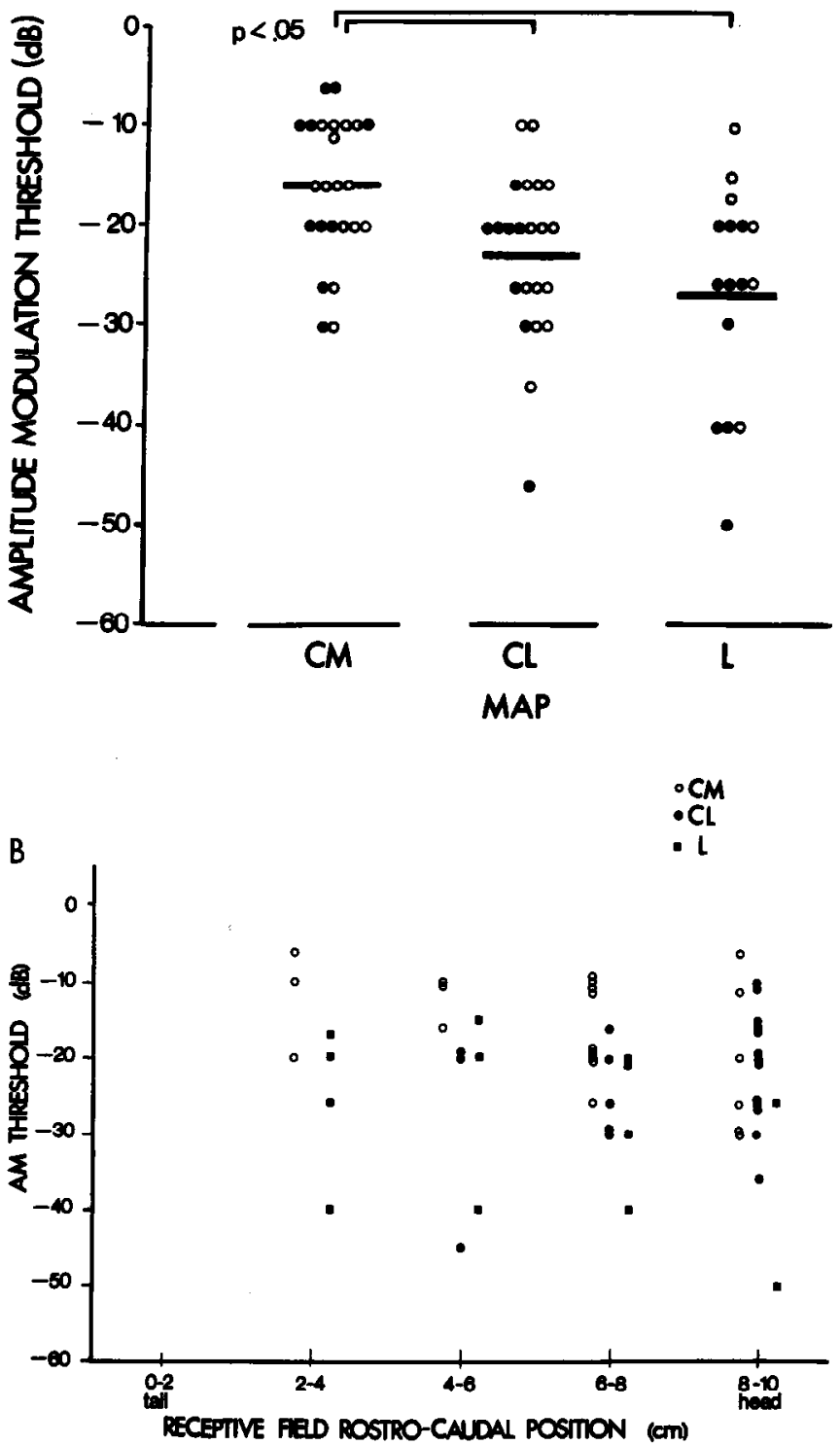

Figure 4. A, Threshold sensitivity to AM for units in the different maps. Filled circles represent $\mathrm{E}$ units; open circles represent I units, and the horizontal lines represent the mean. $0 \mathrm{~dB}=100 \%$ modulation of a $1 \mathrm{mV} / \mathrm{cm}$ stimulus. See Materials and Methods for further details. On average, units in the lateral map are 3 times more sensitive than those in the centromedial map, while units in the centrolateral map are 1.6 times more sensitive. The threshold sensitivity of $E$ and I units did not differ significantly within each map. $B$, Threshold sensitivity to AM versus rostrocaudal position of the receptive field. Open circles, centromedial units; filled circles, centrolateral units; filled squares, lateral units.

quickly as units in the centromedial map $(p<0.05)$. Again, there was no significant difference between $E$ and $I$ units within each map [ $\mathrm{L}$ map: mean peak latency for $\mathrm{E}$ units $=19.4 \pm 3.4$ msec $(n=19)$, mean for I units $=31.6 \pm 7.0 \mathrm{msec}(n=5)$; CL map: $x(\mathrm{E})=33.1 \pm 14.1(n=5), x(\mathrm{I})=33.4 \pm 6.1(n=10)$; and CM map: $x(\mathrm{E})=56.9 \pm 9.4(n=7), x(\mathrm{I})=46.9 \pm 6.8$ $(n=17)]$.

Spontaneous activity of units was approximately the same in the 3 maps: $10.5 \pm 2.7$ spikes/sec for units in the centromedial map $(n=18) ; 12.5 \pm 1.4$ spikes/sec for units in the centrolateral 
A

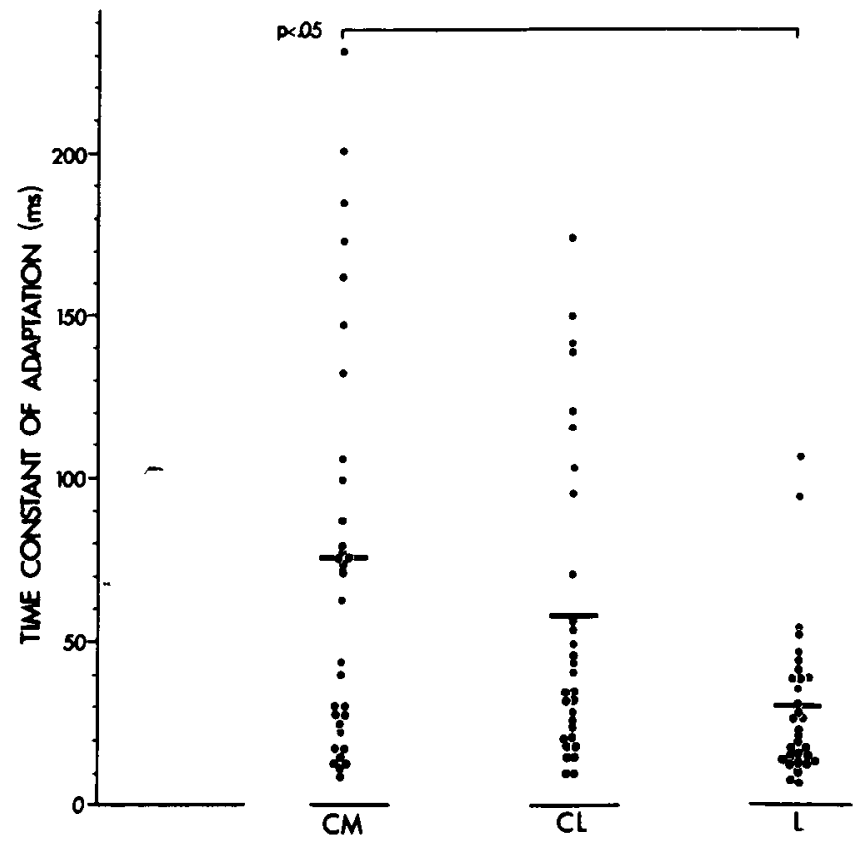

B

\section{E UNIT}

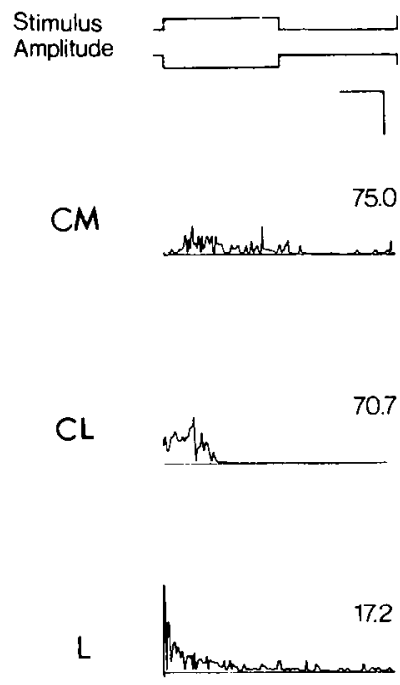

I UNIT

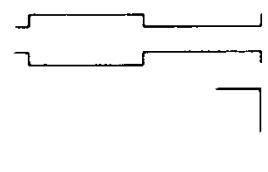

184.0
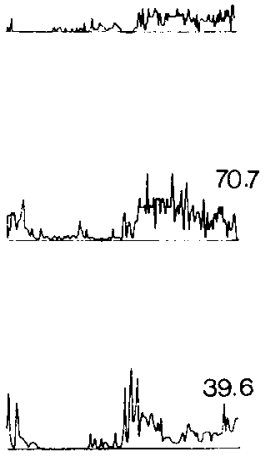

Figure 5. A, Time constant of adaptation of pyramidal cells (both $\mathrm{E}$ and I) in the different maps. Each filled circle represents a single unit, while the horizontal lines indicate the mean. $B$, Average response histograms of pyramidal cell activity in the different maps to a step change in stimulus amplitude. The corresponding time constants of adaptation for each unit are presented above the histograms (msec). These units were chosen as representatives of the average response of pyramidal cells from each map, as shown in $A$. Note the lag in peak response onset for units in the centromedial map. Horizontal calibration bar, $100 \mathrm{msec}$; vertical calibration bar, 0.25 spikes/bin. Bin width is the period of 1 stimulus cycle,

map ( $n=24) ;$ and $9.4 \pm 1.1$ spikes/sec for those in the lateral $\operatorname{map}(n=19)$ (not significant).

Since neurons in the 3 maps responded differently to step changes in amplitude, they were expected to prefer different frequencies of amplitude modulations. The frequency response of pyramidal cells was determined for 19 units in the centromedial and lateral maps and 26 units in the centrolateral map

\section{LATENCY TO PEAK RESPONSE}

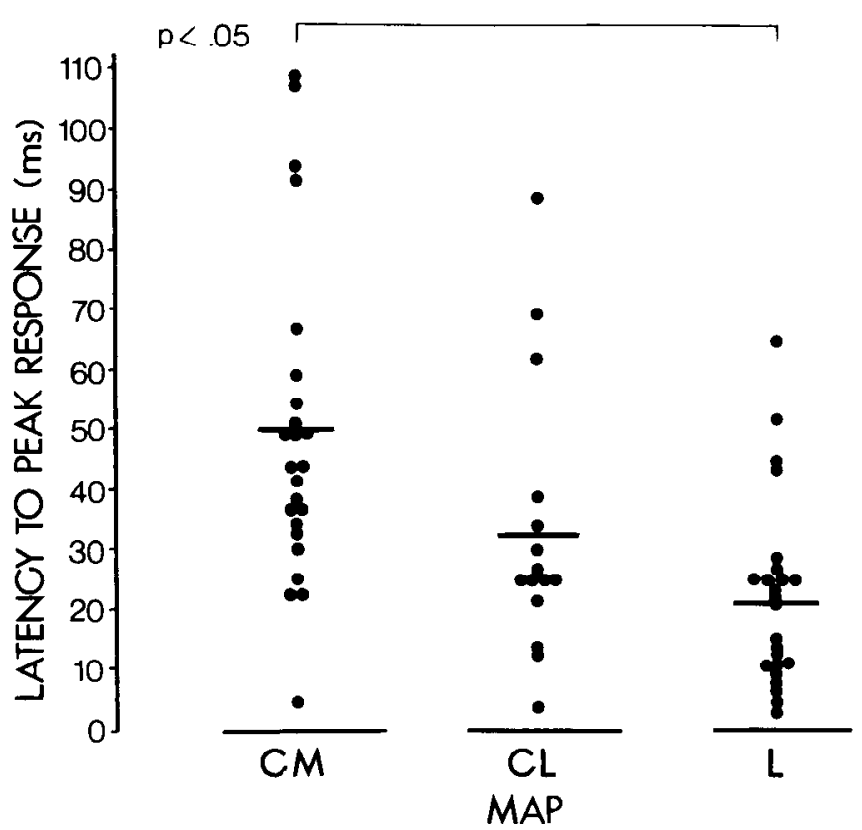

Figure 6. Latency to the peak response to a step change in stimulus amplitude of pyramidal cells (both $\mathrm{E}$ and $\mathrm{I}$ ) in the 3 maps. Each filled circle represents a single unit, while the horizontal lines indicate the mean.

(L map 12 E, 7 I; CL map 10 E, 16 I; CM map 9 E, 10 I). The sensitivity of a unit to different frequencies of amplitude modulation was assessed by recording the average firing frequency (spikes/sec) to a $-10 \mathrm{~dB}$ sinusoidally modulated stimulus, presented at frequencies ranging from 1 to $120 \mathrm{~Hz}$. The average firing frequency was measured over at least 30 modulation cycles.

Predominant types of responses of $E$ and I units from each map are shown in Figure 7. No obvious difference was found between $\mathrm{E}$ and $\mathrm{I}$ units within a given map. Spike rates were normalized by plotting the percentage of the maximum response for each unit. The majority of the lateral map units $(69 \%)$ could be characterized as high-pass filters. [The rest of the lateral map units were broad-band (21\%); low-pass (5\%); and selective for $8 \mathrm{~Hz}(5 \%)$.] Forty-six percent of the centrolateral units showed peaked responses to frequencies between 8 and $16 \mathrm{~Hz}$, while $42 \%$ showed broad-band responses, and $12 \%$ showed high-pass responses. Although the centromedial map units showed the greatest variability, the most common response could be characterized as low-pass (42\%). $26 \%$ of the centromedial units showed high-pass responses; $21 \%$ showed broad-band responses; and $11 \%$ were selective to frequencies between 4 and $10 \mathrm{~Hz}$.

The AM frequency which elicited the maximal response from each neuron was recorded, and histograms of neurons responding maximally within various AM frequency ranges are plotted in Figure 8 for the 3 maps. In support of the data presented in Figure 7, the greatest number of units in the centromedial map prefer low frequencies of $1-3 \mathrm{~Hz}$, while those in the lateral map prefer higher frequencies of $64-120 \mathrm{~Hz}$.

\section{Discussion}

Electric fish sense phase and amplitude distortions of their electric field caused by the EODs of neighboring conspecifics or by 
CM

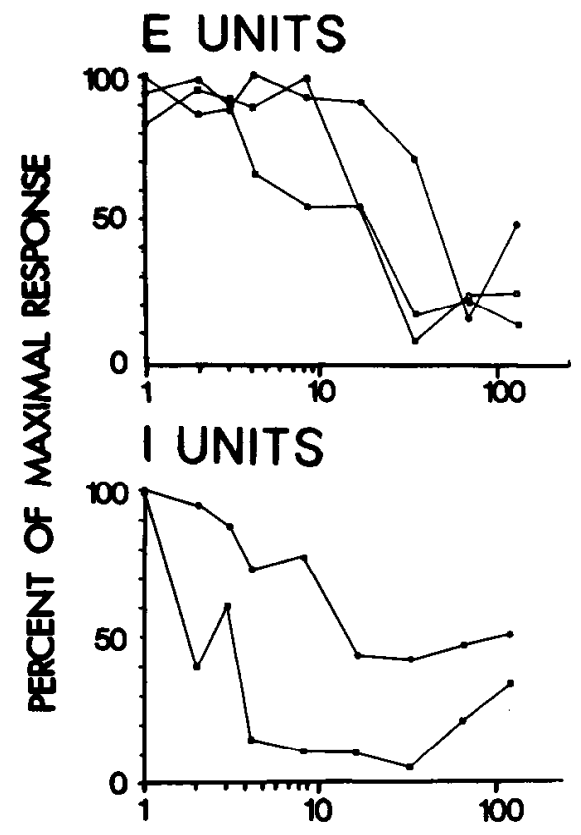

$\mathrm{CL}$
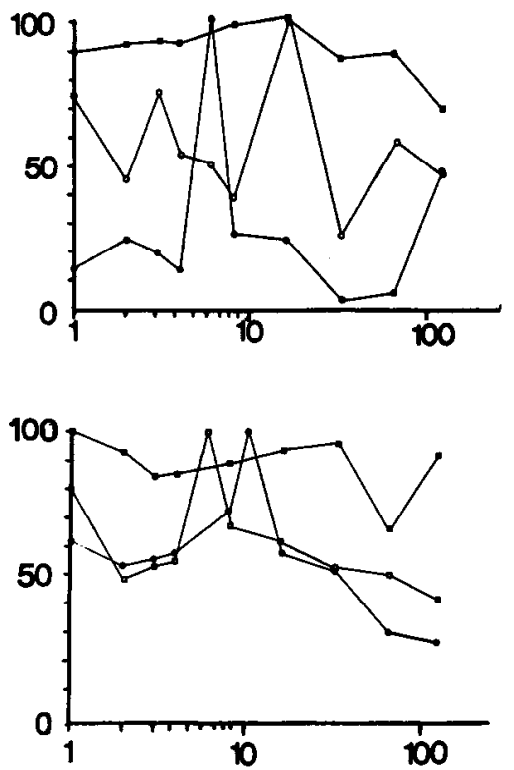

FREQUENCY OF AM (Hz)
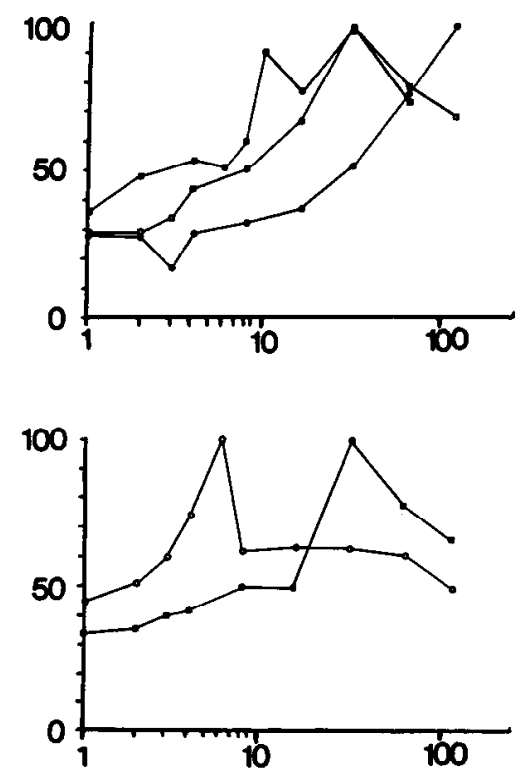

Figure 7. Representative plots of the predominant $\mathrm{E}$ and I cell responses in the 3 maps to various frequencies of AM. Ordinate: percentage of maximum number of spikes/sec. Each symbol represents a different unit. The majority of units in the lateral map (69\%) could be characterized as high-pass filters, while the most common response of units in the centromedial map was low-pass (42\%). Most units in the centrolateral map showed either selective $(46 \%)$ or broad-band responses $(42 \%)$.

objects. These stimuli are represented by the spatial and temporal profile of tuberous electroreceptor activity. P-type electroreceptors adapt only partially, with time constants of approximately $2 \mathrm{sec}$ (Scheich et al., 1973; Hopkins, 1976; Shumway and Maler, 1989); their level of activity, therefore, conveys information about both the steady-state amplitude of the local electric field as well as its changes. Pyramidal cells, on the other hand, respond almost exclusively to changes in amplitude, caused by either the movement of an object relative to the fish or by the interaction of the fish's EOD with that of a neighbor (Enger and Szabo, 1965; Bastian, 1981b).

The electric sense is part of the acousticolateralis system, which includes hearing, the vestibular system, and the lateral line system. Multiple sensory representations are a common feature of the auditory system in vertebrates; they are known to occur in frogs, birds, and mammals (Suga, 1982; Winer and Morest, 1983a, b; Takahashi et al., 1984; Konishi, 1986; Hall and Feng, 1987). It is generally assumed that multiple maps represent parallel processing of different sensory features; however, since most maps in the CNS maintain a topographic representation of the sensory epithelia, it is possible that mapping may be an anatomical construct and not a functional one (see Ulinski, 1984). The functional importance of mapping of a sensory variable has, however, been convincingly demonstrated in 2 cases, in the synthesis of a map of auditory space in the barn owl midbrain (Sullivan and Konishi, 1984; Takahashi et al., 1984; Konishi, 1986) and in the creation of maps of target range, velocity, and target angle in the bat auditory cortex (Suga, 1982).

\section{Pyramidal neurons among the multiple maps have different spatial and temporal characteristics}

The principal findings of this study are that the multiple electrosensory tuberous maps in the ELL of the weakly electric gymnotiform fish Eigenmannia differ significantly in a number of physiological parameters, even though they receive apparently identical patterns of afferent input. As summarized in Table 1, pyramidal neurons in the lateral map, relative to those

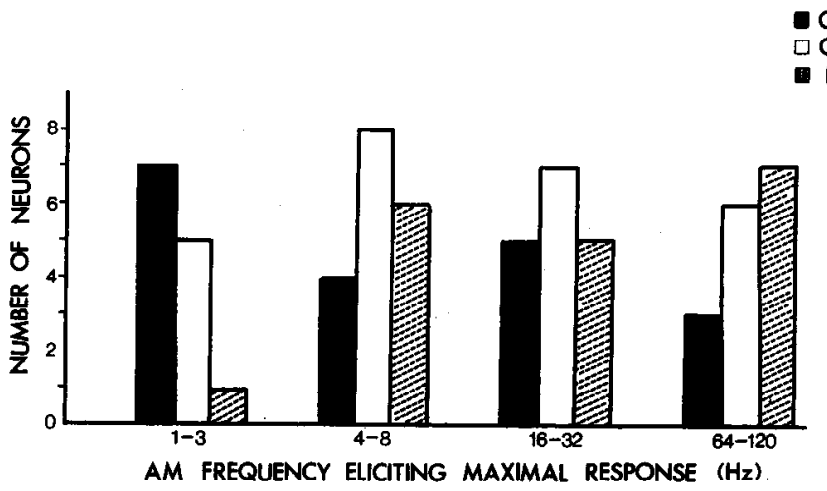

Figure 8. Frequencies of AM eliciting the maximal response for each neuron. This bar graph shows the number of neurons in the 3 maps responding maximally within each given $\mathrm{AM}$ frequency range. Units in the centromedial map prefer low frequencies, while units in the lateral map prefer higher frequencies. Solid bars, centromedial units; white bars, centrolateral units; and hatched bars, lateral units. 
Table 1. Average physiological properties of pyramidal neurons in the 3 ELL maps

\begin{tabular}{llll} 
& Map & & \\
\cline { 2 - 4 } Physiological property & CM & CL & L \\
\hline Receptive-field size & Small & Medium & Large \\
Receptive-field organization & Center-surround & Center-surround & Center-surround \\
Strength of surround inhibition & Strong & Medium & Weak \\
AM sensitivity & Low & Medium & High \\
Rate of adaptation & Slow & Medium & Fast \\
Latency to maximum response & Long & Medium & Short \\
Temporal frequency response & & & \\
(modal response) & Low-pass & Band-pass & High-pass \\
\hline
\end{tabular}

Receptive field size, AM sensitivity, time rate of adaptation, and latency to maximum response differ significantly between units in the $\mathrm{CM}$ and $\mathrm{L}$ map. AM sensitivity also differs significantly between units in the CM and L maps (Tukey test, $p<0.05$ ).

in the centromedial map, generally have larger receptive fields, are more sensitive, respond with a shorter latency to a step change in amplitude (measured with respect to the peak response), adapt much more quickly, and respond to higher frequencies of AMs. Pyramidal neurons in the centromedial map have very small receptive fields similar in size to those of the primary afferents, and nearly half of the cells respond best to low frequencies of AMs. Furthermore, neurons in the centromedial map show a pronounced lag in peak response to a rapid (step) change in amplitude. Neurons in the centrolateral map have properties intermediate to those of the other 2 maps. Additionally, most cells show a center-surround organization, but the strength of inhibition is greatest for units in the centromedial map.

These findings suggest that the 3 maps constitute a set of broadly tuned spatial and temporal filters, with each map carrying both unique and redundant information. Spatial and temporal properties of pyramidal cells have been shown to be dynamically controlled in part by GABAergic interneurons, whose activity is in turn regulated by descending feedback systems (Bastian 1986a, b; Shumway and Maler, 1989). The unique information likely to be contained in the maps is discussed below. The redundancies in information among maps may be important for processing at subsequent levels, such as in the torus semicircularis. DeYoe and Van Essen (1988) have recently discussed the value of such redundancy in certain computational strategies in the visual system.

Much is known about how the size, shape, conductivity, velocity, and distance of an object affect the AM of the animal's electric signal (Heiligenberg, 1975; Bastian, 1981a; see Bastian, $1986 \mathrm{c}$, for review). This knowledge suggests what different kinds of amplitude information might be conveyed by the multiple maps. The exploratory behavior of a fish consists of repeated swimming back and forth past an object, with the fish often bending its tail around the object. The animal has control over both the distance and velocity relative to the object. These 2 parameters greatly affect the magnitude and time course of the EOD distortion. The voltage change due to an object decreases rapidly with increasing distance, decaying as the -1.7 th power of object distance over a $2-20 \mathrm{~mm}$ range lateral to the fish (Bastian, 1981a). Bastian has shown that the responses of pyramidal cells in Apteronotus decay less rapidly as a function of distance, decaying with the -0.78 th power of object distance over the same range. Increases in relative object velocity result in AMs of shorter durations and, hence, of higher temporal frequencies. Increases in object size result in AMs of longer duration and therefore of lower temporal (and spatial) frequencies; the greatest effect of object size, however, is an increase in the amplitude of the EOD distortion.

While the shape of the EOD distortion caused by another fish has not been studied in detail, it is clear that the distortions of the EOD by an object will differ from those caused by the EOD of a neighboring conspecific. AMs caused by a neighbor occur over a much larger portion of the body surface, and the AM frequency is the difference frequency between the EODs of the 2 fish. As the fish move relative to each other, the spatial profile of the AMs on their body surface is modulated accordingly.

The large receptive field size of most lateral map units and their preference for high temporal frequencies suggest that they should respond best to large objects moving rapidly, and they should be able to detect objects at greater distances than cells in the centromedial map. As most pyramidal cells in the lateral map do not show a strong surround inhibition, they should also vigorously respond to the AMs caused by the interaction of the animal's EOD with that of a neighboring conspecific. The weaker surround inhibition in these cells is at least partially a consequence of the increased strength of the excitatory center.

Pyramidal cells in the centromedial map, because of their small receptive fields and strength of surround inhibition, should be capable of resolving fine spatial detail. Their low sensitivity suggests they would respond only when an object was at close range. The stronger surround inhibition of these cells also suggests that they should not respond as vigorously to the AMs generated by interaction of their EOD with the EOD of a neighbor, which, in most circumstances, would stimulate both the center and surround simultaneously.

One of the most surprising findings of this study was the poor response of centromedial cells to rapid (both step changes and high frequency AMs) changes in stimulus amplitude (step) and their preference for low frequencies of AMs. These results suggest that centromedial cells should be useful primarily at low object velocities. The lag in peak response of centromedial cells to step changes in amplitude is probably not due to differences in afferent latencies, as all maps receive identical afferent input. This lag may result from (1) different afferent synaptic properties, (2) different biophysical properties of centromedial cells, or (3) it may be a consequence of inhibitory synaptic inputs, as shown for.X-lag cells in the cat (Mastronarde, 1987b). 
What is the functional significance of physiological differences among classes of pyramidal cells?

These results suggest that there are at least 2 physiologically distinct classes of pyramidal neurons located in the lateral and centromedial maps of the ELL, despite the fact that the response properties of neurons in the present sample overlapped to some degree among maps. Since the results were obtained from a large number of fish, it is likely that the overlap in some properties is due to animal variability. Proving that the pyramidal cells can be divided into physiologically distinct categories will require examination of response properties from a large number of cells among maps in individual fish. One can hypothesize, however, that the physiologically distinguishable types of pyramidal cells in the ELL subserve 4 functions which are not mutually exclusive:

1. Individual nerve fibers are limited in their dynamic range of coding. The different types of pyramidal cells among the multiple maps thus could expand the dynamic range of the electrosensory system. A similar increase in dynamic range is apparently achieved in mormyriform fish; this increase, however, begins at the receptor level. Mormyromast electroreceptors, used in electrolocation, are of 2 structural types, A and B (S7abo and Wersäll, 1970). Bell (1987) has recently shown that the type-A afferents have a higher threshold than the type-B afferents. Mormyriforms have 2 maps in the ELL which receive input from the mormyromast afferents, the medial zone and the dorsolateral zone. Unlike the multiple maps in gymnotiform fish, these 2 maps receive different afferent input, as type-A afferents project exclusively to the medial zone and type-B afferents project exclusively to the dorsolateral zone. Possible differences in processing within the 2 ELL maps of mormyriform fishes have not yet been examined.

2. Theoretically, given identical receptor input to a class of sensory neurons, an inverse relationship exists between spatial resolution and sensitivity to small modulations of signal amplitude. The larger the receptive field, the greater the convergence of receptor inputs; this reduces the capacity for spatial resolution but at the same time renders a unit more sensitive. The converse is true for small receptive fields. Having different classes of pyramidal cells devoted either to the processing of spatial detail or the detection of small signal modulations means that the animal does not need to sacrifice one for the other.

3. At least in one other sensory system, the visual system, the size of receptive fields appears to be often correlated with the response to temporal frequencies (for review, see Stone et al., 1979); units with small receptive fields are responsive to slowmoving stimuli (i.e., lower temporal frequencies), and units with large receptive fields are selective for higher temporal frequencies. Having classes of pyramidal cells with different spatial and temporal characteristics ensures both spatial and temporal resolution.

4. Different classes of pyramidal cells among the ELL maps may provide the substrate for independent gain control used in different behavioral circumstances, as initially suggested by Bastian (1986a). Similar proposals have been made for the role of the lateral geniculate nucleus in mammals (Sherman and Koch, 1986). The maps receive different descending input from the nucleus praeeminentialis along with descending input from the posterior eminentia granularis (see Carr and Maler, 1986). This latter descending input has recently been shown to also differ among maps (Shumway, 1989). While the role of the nucleus preaeeminentialis is just beginning to be explored (Bastian and Bratton, 1988), Bastian (1986a, b) has shown that the descending input from the posterior eminentia granularis acts as a gain control to adjust the responsiveness of pyramidal neurons in the face of varying mean stimulus amplitudes.

\section{The ELL is a model system for testing the functional significance of multiple sensory maps}

What is the functional significance of multiple sensory maps? Proving the functional significance of a mammalian cortical map is difficult, given the numerous corticocortical and corticothalamic interconnections of the multiple areas. Because of the redundancies of information caused by the many interconnections, interpretation of behavioral deficits caused by lesions of any given map is problematic. A behavioral deficit does not prove that a particular map is necessary and sufficient for a particular sensory parameter, although it does indicate the importance of the map in that information stream (Randolph and Semmes, 1970; Newsome et al., 1985; Newsome and Paré, 1988). Negative results are inconclusive: if no deficit is observed, perhaps the behavioral tests are too crude, and fine-grained behavioral examination would uncover some effect. Alternatively, given the well-established reorganization within sensory systems following injuries (Merzenich et al., 1983, 1984), the lesion may cause some path not previously involved in that particular function to be used.

The maps in the ELL may provide a simpler system in which to address the functional importance of multiple sensory representation through chemical lesion studies and behavioral analysis. The identical afferent input, the lack of intermap connections, and the segregation of descending input simplify the task. Furthermore, the spatial and temporal characteristics of the physiologically distinct neurons in the ELL maps can also be examined in vitro (Mathieson and Maler, 1988).

\section{Electrosensory processing shares numerous similarities with sensory processing in other systems}

The search for common design features in sensory processing enables us to understand evolutionary and anatomical constraints placed on sensory systems. At early stages of electrosensory processing, as represented by E and I pyramidal cells, the electrosensory system shares a number of similarities with other vertebrate sensory systems. Similarities with the visual system include center-surround receptive-field organization for enhancement of spatial contrast, oN and off center neuronal classes (E and I units in the ELL, respectively), and the existence of separate classes of neurons with different temporal and spatial filter characteristics $[X, Y$, and $W$ ganglion cells in the cat (Sherman, 1979); pyramidal cells in the multiple maps of the ELL]. Furthermore, the responses of X-lag cells in the lateral geniculate nucleus to the onset of a spot of light resemble the delayed responses of centromedial neurons to a step change in amplitude (Mastronarde, 1987a, b; Humphrey and Weller, 1988). Neuronal responses in the lateral geniculate, much as the responses of neurons in the multiple maps of the ELL, are adjusted by descending input (Bastian, 1986a, b; Sherman and Koch, 1986).

The 2 cutaneous maps within the mammalian somatosensory cortex, areas $3 \mathrm{~b}$ and 1 , have different receptive-field sizes even though they receive collaterals from the same thalamic nucleus (Merzenich et al., 1981). The larger size of the receptive fields in area 1 may be due to greater convergence of afferents from the ventroposterior nucleus (Kaas, 1983), much as demonstrat- 
ed in the following paper on anatomical differences in the $3 \mathrm{ELL}$ maps (Shumway, 1989). Furthermore, the map with the smaller receptive-field sizes, area $3 b$, has a greater proportion of neurons which adapt slowly (Paul et al., 1972; Sur, 1980). Unlike the ELL maps, in which the strength of surround inhibition is strongest in the map with the smallest receptive fields, a centersurround receptive-field organization was found in area 1 , while the receptive fields of cells in area $3 \mathrm{~b}$ were homogeneous (Sur, 1980).

In all systems, the receptive-field size of neurons receiving similar or identical afferent input differs only by a factor of 23: receptive-field sizes of $\mathrm{X}$ ganglion cells in the fovea centralis of the cat are $0.1^{\circ}$, while those of Y ganglion cells are $0.3^{\circ}$. Similar differences are found between $\mathbf{P}$ and $\mathbf{M}$ ganglion cells in the monkey retina (Shapley and Perry, 1986) and between units in areas $3 \mathrm{~b}$ and 1 of the somatosensory cortex (Sur et al., 1980; Merzenich et al., 1981). Some response properties of neurons in the owl nucleus angularis and magnocellularis, including dynamic range, sensitivity, and maximum response, also show a similar degree of difference (Sullivan and Konishi, 1984). These similarities may reflect structural limits to the reorganization of afferent input within different areas and pathways.

\section{References}

Bastian, J. (1981a) Electrolocation. I: An analysis of the effects of moving objects and other electrical stimuli on the electroreceptor activity of Apteronotus albifrons. J. Comp. Physiol. 144: 465-479.

Bastian, J. (1981b) Electrolocation. II: The effects of moving objects and other electrical stimuli on the activities of two categories of posterior lateral line lobe cells in Apteronotus albifrons. J. Comp. Physiol. 144: $481-494$.

Bastian, J. (1986a) Gain control in the electrosensory system mediated by descending inputs to the electrosensory lateral line lobe. J. Neurosci. 6: 553-562.

Bastian, J. (1986b) Gain control in the electrosensory system: A role for the descending projection to the electrosensory lateral line lobe. J. Comp. Physiol. 158: 505-515.

Bastian, J. (1986c) Electrolocation: Behavior, anatomy, and physiology. In Electroreception, T. H. Bullock and W. Heiligenberg, eds., pp. 577-612, Wiley, New York.

Bastian, J., and B. O. Bratton (1988) The nucleus praeeminentialis; Properties of neurons providing descending inputs to the electrosensory lateral line lobe of weakly electric fish. Soc. Neurosci. Abstr. 14: 311.

Bell, C. (1987) Central termination of afferents from mormyromast electroreceptors. Soc. Neurosci. Abstr. 13: 623.

Bell, C., and T. Szabo (1986) Electroreception in mormyrid fish: Central anatomy. In Electroreception, T. H. Bullock and W. Heiligenberg, eds., pp. 375-421, Wiley, New York.

Boord, R. L., and G. L. Rasmussen (1963) Projection of the cochlear and lagenar nerves on the cochlear nuclei of the pigeon. J. Comp. Neurol. 120: 463-475.

Carr, C., and L. Maler (1986) Electroreception in gymnotiform fish: Central anatomy and physiology. In Electroreception, T. H. Bullock and W. Heiligenberg, eds., pp. 319-373, Wiley, New York.

Carr, C. E., W. Heiligenberg, and G. J. Rose (1986) A time-comparison circuit in the electric fish midbrain. I. Behavior and physiology. J. Neurosci. 6: 107-119.

DeYoe, E. A., and D. C. Van Essen (1988) Concurrent processing streams in monkey visual cortex. Trends Neurosci. 11: 219-226.

Enger, P. S., and T. Szabo (1965) Activity of central neurons involved in electroreception in some weakly electric fish (Gymnotidae). J. Neurophysiol. 28: 800-818.

Frank, K., and M. C. Becker (1964) Microelectrodes for recording and stimulation. In Physical Techniques in Biological Research, Vol. 5, part A, W. L. Nastuk, ed., pp. 23-84, Academic, New York.

Hall, J. C., and A. S. Feng (1987) Evidence for parallel processing in the frog's auditory thalamus. J. Comp. Neurol, 258: 407-419.

Heiligenberg, W. (1975) Theoretical and experimental approaches to spatial aspects of electrolocation. J. Comp. Physiol. 103: 247-272.
Heiligenberg, W. (1986) Jamming avoidance responses: Model systems for neuroethology. In Electroreception, T. H. Bullock and W. Heiligenberg, eds., pp. 577-612, Wiley, New York.

Heiligenberg, W., and J. Dye (1982) Labelling of electroreceptive afferents in a gymnotoid fish by intracellular injection of HRP: The mystery of multiple maps. J. Comp. Physiol. 148: 287-296.

Hopkins, C. D. (1976) Stimulus filtering and electroreception: Tuberous electroreceptors in three species of gymnotoid fish. J. Comp. Physiol. 14: 171-202.

Hoshimiya, N., K. Shogen, T. Matsuo, and S. Chichibu (1980) The Apteronotus EOD field: Waveform and EOD field simulation. J. Comp. Physiol. 135: 283-290.

Humphrey, A. L., and R. E. Weller (1988) Functionally distinct groups of X cells in the lateral geniculate nucleus of the cat. J. Comp. Neurol. 268: $429-447$

Kaas, J. H. (1982) The segregation of function in the nervous system: Why do sensory systems have so many subdivisions? In Contributions to Sensory Physiology, Vol. 7, W. P. Neff, ed., pp. 201-240, Academic, New York.

Kaas, J. H. (1983) What, if anything, is S1? Organization of first somatosensory area of cortex. Physiol. Rev. 63: 206-231.

Konishi, M. (1986) Centrally synthesized maps of sensory space. Trends Neurosci. 9: 136-138.

Maler, L. (1979) The posterior lateral line lobe of certain gymnotoid fish: Quantitative light microscopy. J. Comp. Neurol. 183: 323-364.

Maler, L., E. Sas, and J. Rogers (1981) The cytology of the posterior lateral line lobe of high frequency electric fish (Gymnotidae): Dendritic differentiation and synaptic specificity in a simple cortex. $J$. Comp. Neurol. 158: 87-141.

Mastronarde, D. M. (1987a) Two classes of single-input X-cells in cat lateral geniculate nucleus. I. Receptive-field properties and classification of cells. J. Neurophysiol. 57: 357-380.

Mastronarde, D. M. (1987b) Two classes of single-input X-cells in cat lateral geniculate nucleus. II. Retinal inputs and the generation of receptive-field properties. J. Neurophysiol. 57: 381-413.

Mathieson, W. B., and L. Maler (1988) Morphological and electrophysiological properties of a novel in vitro preparation: The electrosensory lateral line lobe brain slice. J. Comp. Physiol. 163: 489-506.

Matsubara, J. (1982) Physiological cell types in the posterior lateral line lobes of weakly electric fish: Neural correlates of electrolocation under jamming. J. Comp. Physiol. 149: 339-352.

Merzenich, M. M., M. Sur, R. J. Nelson, and J. H. Kaas (1981) Organization of the $\mathrm{S} 1$ cortex: Multiple cutaneous representations in areas $3 \mathrm{~b}$ and 1 of the owl monkey. In Cortical Sensory Organization, Vol. 1: Multiple Somatic Areas, C. N. Woolsey, ed., pp. 47-66, Humana Press, Clifton, NJ.

Merzenich, M. M., J. H. Kaas, J. T. Wall, M. Sur, R. J. Nelson, and D. J. Felleman (1983) Progression of change following median nerve section in the cortical representation of the hand in areas $3 \mathrm{~b}$ and 1 in adult owl and squirrel monkeys. Neuroscience 3: 639-665.

Merzenich, M. M., R. J. Nelson, M. P. Stryker, M. S. Cynader, A. Schoppmann, and J. M. Zook (1984) Sormatosensory cortical map changes following digit amputation in adult monkeys. J. Comp. Neurol. 224: 591-605.

Newsome, W. T., and E. B. Paré (1988) A selective impairment of motion perception following lesions of the middle temporal area (MT). J. Neurosci. 8: 2201-2211.

Newsome, W. T., R. H. Wurtz, M. R. Dürsteler, and A. Mikami (1985) Deficits in visual motion processing following ibotenic acid lesions of the middle temporal visual area of the macaque monkey. J. Neurosci. 5: 825-840.

Partridge, B. L., W. Heiligenberg, and J. Matsubara (1981) The neural basis of a sensory filter in the jamming a voidance response: No grandmother cells in sight. J. Comp. Physiol. 145: 153-168.

Paul, R. L., M. Merzenich, and H. Goodman (1972) Representation of slowly adapting and rapidly adapting cutaneous mechanoreceptors of the hand in Brodmann's areas 3 and 1 of Macaca mulatta. Brain Res. 36: 222-249.

Peters, A., and E. G. Jones, eds. (1985a) Cerebral Cortex, Vol. 4: Association and Auditory Cortices, Plenum, New York.

Peters, A., and E. G. Jones, eds. (1985b) Cerebral Cortex, Vol. 3: Visual Cortex, Plenum, New York.

Peters, A., and E. G. Jones, eds. (1986) Cerebral Cortex, Vol. 5: Sensory-Motor Areas and Aspects of Cortical Connectivity, Plenum, New York. 
Randolph, M., and J. Semmes (1970) Behavioral consequences of selective subtotal ablation in the postcentral gyrus of Macaca mulatta. Brain Res. 70: 55-70.

Rose, G., and W. Heiligenberg (1986) Limits of phase and amplitude sensitivity in the torus semicircularis of Eigenmannia. J. Comp. Physiol. 159: 813-822.

Saunders, J., and J. Bastian (1984) The physiology and morphology of two types of electrosensory neurons in the weakly electric fish Apteronotus leptorhynchus. J. Comp. Physiol. 154: 199-209.

Scheich, H. (1977) Neural basis of communication in the high frequency electric fish, Eigenmannia virescens (jamming avoidance response). III: Central integration in the sensory pathway and control of the pacemaker. J. Comp. Physiol. 113: 229-255.

Scheich, H., T. H. Bullock, and R. H. Hamstra (1973) Coding properties of two categories of afferent nerve fibers: High frequency electroreceptors in the electric fish, Eigenmannia. J. Neurophysiol. 36: 39-60.

Shapley, R., and Perry (1986) Cat and monkey retinal ganglion cells and their visual functional roles. Trends Neurosci. 9: 229-235.

Sherman, S. M. (1979) The functional significance of $X$ and $Y$ cells in normal and visually deprived cats. Trends Neurosci. 2: 192-195.

Sherman, S. M., and C. Koch (1986) The control of retinogeniculate transmission in the mammalian lateral geniculate nucleus. Exp. Brain Res. 63: 1-20.

Shumway, C. A. (1985) Pyramidal cells in the multiple electrosensory maps of the electrosensory lateral line lobe (ELL) have a centersurround receptive field. Soc. Neurosci. Abstr. 11: 269.

Shumway, C. A. (1986) Physiological differences in the multiple maps of the electrosensory lateral line lobe (ELL): Pyramidal cells have different receptive field sizes. Soc. Neurosci. Abstr. 12: 201.

Shumway, C. (1989) Multiple electrosensory maps in the medulla of weakly electric gymnotiform fish. II. Anatomical differences. J. Neurosci. 9: 4400-4415.

Shumway, C., and L. Maler (1989) GABAergic inhibition shapes temporal and spatial response properties of pyramidal cells in the electrosensory lateral line lobe of gymnotoid fish. J. Comp. Physiol. 164: $391-407$.
Stone, J., B. Dreher, and A. Leventhal (1979) Hierarchical and parallel mechanisms in the organization of visual cortex. Brain Res. Rev. 1: 345-394.

Suga, N. (1981) Functional organization of the auditory cortex: Representation beyond tonotopy in the bat. In Cortical Sensory Organization, Vol. 3: Multiple Auditory Areas, C. N. Woolsey, ed., pp. 157-218, Humana Press, Clifton, NJ.

Sullivan, W. E., and M. Konishi (1984) Segregation of stimulus phase and intensity coding in the cochlear nucleus of the barn owl. J. Neurosci. 4: 1787-1799.

Sur, M. (1980) Receptive fields of neurons in areas $3 \mathrm{~b}$ and 1 of somatosensory cortex in monkeys. Brain Res. 198: 465-477.

Sur, M., M. M. Merzenich, and J. H. Kaas (1980) Magnification, receptive-field area, and "hypercolumn" size in areas $3 \mathrm{~b}$ and 1 of somatosensory cortex in owl monkeys. J. Neurophysiol. 44: 295-311.

Szabo, T., and J. Wersäll (1970) Ultrastructure of an electroreceptor (mormyromast) in a mormyrid fish, Gnathonemus petersii. J. Ultrastruct. Res. 30: 473-490.

Takahashi, T., A. Moiseff, and M. Konishi (1984) Time and intensity cues are processed independently in the auditory system of the owl. J. Neurosci. 4: 1781-1786.

Ulinski, P. S. (1984) Design features in vertebrate sensory systems. Am. Zool. 24: 717-731.

Winer, J. A., and D. K. Morest (1983a) The medial division of the medial geniculate body of the cat: Implications for thalamic organization. J. Neurosci. 3: 2629-2651.

Winer, J. A., and D. K. Morest (1983b) The neuronal architecture of the dorsal division of the medial geniculate body of the cat: A study with the rapid Golgi method. J. Comp. Neurol. 221: 1-30.

Woolsey, C. N., ed. (1981a) Cortical Sensory Organization, Vol. I: Multiple Somatic Areas, Humana Press, Clifton, NJ.

Woolsey, C. N., ed. (1981b) Cortical Sensory Organization, Vol. 2: Multiple Visual Areas, Humana Press, Clifton, NJ.

Woolsey, C. N., ed. (1982) Cortical Sensory Organization, Vol. 3: Multiple Auditory Areas. Humana Press, Clifton, NJ. 